\title{
PARITY PRICE OF AGRICULTURAL PRODUCTS, ENERGY AND MATERIAL RESOURCES
}

\author{
ЦЕНОВАЯ ПАРИТЕТНОСТЬ СЕЛЬСКОХОЗЯЙСТВЕННОЙ ПРОДУКЦИИ, \\ ЭНЕРГЕТИЧЕСКИХ И МАТЕРИАЛЬНО-ТЕХНИЧЕСКИХ РЕСУРСОВ
}

\author{
A. Alpatov, Canditate of Economic Sciences \\ А.В. Алпатов, кандидат экономических наук
}

\begin{abstract}
All-Russia Scientific Research Institute of Rural Economics, Moscow, Russia
ВНИИ экономики сельского хозяйства, г. Москва, Россия

Phone: +7 (4862) 45-37-42, E-mail: anthonyalpatov@yandex.ru
\end{abstract}

Received February 5, 2012

\begin{abstract}
The article describes the main approaches to parity of agricultural products to energy and material resources, are the price indices for certain types of energy resources, and presents data on the availability of agricultural machinery in agricultural organizations of the Russian Federation. The dynamics of growth in energy prices in relation to the specific energy consumption per 1 ha of sown area in the agricultural organizations of the Russian Federation, the consumption of resources such as petroleum products, electricity and fuel. In addition, the article shows the average sales price for agricultural products and logistical resources. Shown the equivalence of the exchange of products between agriculture and industry.
\end{abstract}

\section{АННОТАЦИЯ}

В статье рассмотрены основные подходы в паритетности сельскохозяйственной продукции с энергетическими и материально-техническими ресурсами, указаны индексы изен на отдельные виды энергетических ресурсов и представлены данные о наличии сельскохозяйственной техники в сельскохозяйственньх организациях Российской Федераџии. Рассмотрена динамика роста иен на энергоресурсы в увязке с удельным расходом энергоресурсов на 1 га посевной площади в сельскохозяйственных организациях Российской Федераџии, расход ресурсов, таких как нефтепродукты, электроэнергия и топливо. Кроме того, в статье представлены средние цень реализации на сельскохозяйственную продукцию и материально-технические ресурсы. Указана эквивалентность обмена продукиией между сельским хозяйством и промьшиенностью.

\section{KEY WORDS}

Agriculture; Price parity; Energy, material and technical resources; Price; Agricultural machinery; Equivalence; Exchange.

\section{КЛЮЧЕВЫЕ СЛОВА}

Сельское хозяйство; Ценовой паритет; Энергоресурсы; Материально-технические ресурсы; Цена; Сельскохозяйственная техника; Эквивалентность; Обмен.

Рост объемов производства сельскохозяйственной продукции и увеличение обеспеченности собственными продуктами питания, намеченный «Доктриной продовольственной безопасности» должен сопровождаться снижением ее себестоимости благодаря экономии энергоресурсов. Это обуславливается постоянным ростом цен. Например, за 2004-2009 гг. цена электроэнергии для сельхозтоваропроиз- водителей выросла в 5,2 раза, горюче и смазочные материалы - в 2,6 раза, топливо - в 4,5 раза. В связи с этим необходима разработка организационно-экономического механизма энергосбережения, который должен применяться в сельскохозяйственных предприятиях, региональных и федеральном органах управления сельским хозяйством. 
Таблица 1 - Индексы цен на отдельные виды энергетических ресурсов, приобретенных сельскохозяйственными организациями по Российской Федерации в среднем за год, в \% к предыдущему году*

\begin{tabular}{|c|c|c|c|c|c|c|c|c|}
\hline Вид энергоресурсов & 2002 & 2003 & 2004 & 2005 & 2006 & 2007 & 2008 & 2009 \\
\hline Промышленные товары & 112,1 & 118,6 & 124,7 & 115,7 & 110,7 & 112,2 & 125,0 & 96,8 \\
\hline Топливо - всего & 127,5 & 131,9 & 121,4 & 124,5 & 111,4 & 114,1 & 124,9 & 111,4 \\
\hline - древесина топливная & - & 115,7 & 118,6 & 114,6 & 117,2 & 116,4 & 116,8 & 108,8 \\
\hline - уголь & 115,8 & 114,0 & 118,1 & 121,7 & 113,3 & 109,8 & 128,3 & 113,4 \\
\hline - торф & 123,1 & 112,6 & 143,4 & 121,2 & 110,8 & 126,6 & 119,3 & 135,1 \\
\hline - нефть & - & 110,8 & 128,4 & 147,6 & 127,8 & 106,0 & 132,9 & 84,9 \\
\hline $\begin{array}{l}\text { - газ горючий природный } \\
\text { (газ естественный) }\end{array}$ & 130,5 & 136,0 & 121,7 & 124,7 & 110,8 & 115,1 & 125,2 & 113,6 \\
\hline - газ горючий природный сжиженный & 125,8 & 129,2 & 125,0 & 121,7 & 109,3 & 113,9 & 113,2 & 101,2 \\
\hline Горючее и смазочные материалы - всего & 103,6 & 120,4 & 128,9 & 125,1 & 113,3 & 104,5 & 131,1 & 81,9 \\
\hline Бензины автомобильные & 106,9 & 121,1 & 130,3 & 120,1 & 116,8 & 107,9 & 118,6 & 91,2 \\
\hline $\begin{array}{l}\text { Керосины, включая топливо } \\
\text { реактивное керосиновое }\end{array}$ & 109,4 & 113,6 & 125,2 & 134,7 & 114,3 & 119,7 & 131,0 & 85,9 \\
\hline Топливо дизельное & 102,0 & 120,7 & 128,5 & 126,9 & 111,4 & 102,4 & 135,2 & 78,1 \\
\hline Maзyт & 110,8 & 109,5 & 107,3 & 142,1 & 133,8 & 103,6 & 134,6 & 93,6 \\
\hline Масла смазочные (нефтяные) & 105,8 & 112,4 & 128,1 & 117,0 & 128,3 & 110,8 & 135,2 & 90,2 \\
\hline Электроэнергия & 143,4 & 128,8 & 119,6 & 123,0 & 115,1 & 116,0 & 118,0 & 122,3 \\
\hline Тепловая энергия & - & 115,7 & 118,5 & 113,7 & 119,7 & 112,4 & 116,2 & 115,3 \\
\hline
\end{tabular}

* http://www.gks.ru/wps/wcm/connect/rosstat/rosstatsite/main/price

В соответствии с Федеральным законом «Об энергосбережении» под энергосбережением понимается реализация правовых, организационных и экономических мер, направленных на эффективное использование энергетических ресурсов и вовлечение в хозяйственный оборот возобновляемых источников энергии; под энергосберегающей политикой государства - это правовое, организационное и финансово-экономическое регулирование деятельности в области энергосбережения.

Экономический механизм энергосбережения формируется на основе основных направлений снижения энергоемкости продукции: технические, технологические, организационные, которые они мало внедряются на практике. Успешной реализации этих резервов будет способствовать:

- определение показателей и анализ энергопотребления и энергосбережения;

- технико-экономическое обоснование технологических и технических мероприятий по энергосбережению в том числе производства и применения альтернативных видов топлива; - разработка форм и методов государственной поддержки энергосбережения на федеральном и региональном уровне;

- разработка рекомендаций по экономическому механизму энергосбережения в сельскохозяйственных предприятиях;
- экономические взаимоотношения с поставщиками энергоресурсов;

- разработка нормативов энергопотребления и энергоэффективности.

Основными видами энергоресурсов, потребляемых в сельском хозяйстве являются: дизельное топливо и бензин, электроэнергия, природный газ, мазут, каменный уголь, дрова, торф и альтернативные виды: биотопливо и биогаз, энергия солнца и ветра. Для оценки состояния энергопотребления проводят анализ наличия технических средств - потребителей энергоресурсов и их энергетические мощности, энергооснащенность и расхода энергоресурсов. При анализе используют общие и удельные показатели. К последним относятся энергоемкость - расход (потребление) энергоресурсов в физическом (кг или Мдж) и стоимостном выражении (руб.) на 1 гектар, голову скота; 1 ц и 1000 руб. произведенной продукции.

Организационно-экономический механизм энергосбережения в сельскохозяйственном производстве предусматривает технологическую и техническую модернизацию и освоение инновационных технологий и техники, повышение производительности труда и ресурсосбережения в сельском хозяйстве. Одним из ключевых направлений развития энергосберегающего сельского хозяйства является 
обновление технической базы. За последние годы машинотракторный парк АПК России значительно изменился как количественно, так и качественно. Ввиду своей специфики аграрное производство энергоемкое. Поэтому актуальным вопросом является его техническое оснащение, которое в современных условиях выступает лимитирующим фактором повышения эффективности сельского хозяйства. Современная ситуация на рынке сельскохозяйственной продукции диктует необхо- димость производства продукции высокого качества с наименьшей себестоимостью. Это возможно лишь при использовании современной техники, позволяющей снизить энергоемкость производства.

В целом оснащение сельхозпроизводства в России техникой характеризуется отрицательной динамикой. В табл. 2 представлены данные о наличии сельскохозяйственной техники.

Таблица 2 - Парк техники в сельскохозяйственных организациях России, тыс. шт.*

\begin{tabular}{|c|c|c|c|c|c|c|c|}
\hline Вид техники & 2005 & 2006 & 2007 & 2008 & 2009 & 2010 & $\begin{array}{c}2010 \\
\text { в } \% \text { K } 2009\end{array}$ \\
\hline Тракторы & 523,2 & 478,5 & 441,1 & 396,9 & 359,5 & 338,4 & 94,1 \\
\hline Плуги - всего & 148,8 & 132,8 & 121,2 & 106,3 & 94,7 & 87,7 & 92,6 \\
\hline Культиваторы & 175,5 & 162,6 & 153,4 & 138,4 & 127,1 & 119,8 & 94,2 \\
\hline в том числе комбинированные агрегаты & & ל-ביה & 7,1 & 8,1 & 8,5 & 8,8 & 103,0 \\
\hline Машины для посева & & & 184,4 & 166,3 & 151,9 & 142,3 & 93,7 \\
\hline \multicolumn{8}{|l|}{ в том числе: } \\
\hline посевные комплексы & & & 5,6 & 7,3 & 7,7 & 8,3 & 107,8 \\
\hline сеялки & 218,9 & 203,9 & 178,6 & 159,0 & 144,2 & 134,0 & 92,9 \\
\hline \multicolumn{8}{|l|}{ Комбайны: } \\
\hline зерноуборочные & 129,2 & 117,6 & 107,7 & 95,9 & 86,1 & 80,7 & 93,7 \\
\hline кукурузоуборочные & 2,2 & 1,8 & 1,5 & 1,3 & 1,1 & 1,1 & 93,4 \\
\hline кормоуборочные & 33,4 & 29,5 & 26,6 & 24,0 & 21,4 & 20,0 & 93,1 \\
\hline льноуборочные & 1,8 & 1,6 & 1,3 & 1,1 & 0,9 & 0,7 & 83,8 \\
\hline картофелеуборочные & 4,5 & 4,0 & 3,7 & 3,4 & 3,0 & 2,9 & 94,6 \\
\hline Свеклоуборочные машины (без ботвоуборочных) & 7,2 & 6,2 & 5,3 & 4,2 & 3,6 & 3,2 & 89,9 \\
\hline Разбрасыватели твердых минеральных удобрений & 19,7 & 18,7 & 17,9 & 17,4 & 17,0 & 16,6 & 97,5 \\
\hline \multicolumn{8}{|l|}{ Машины для внесения в почву: } \\
\hline твердых органических удобрений & 10,9 & 9,6 & 8,8 & 7,6 & 6,9 & 6,5 & 93,3 \\
\hline жидких органических удобрений & 5,8 & 5,1 & 4,7 & 4,3 & 4,1 & 3,9 & 95,4 \\
\hline Доильные установки и агрегаты - всего & 50,3 & 44,0 & 39,8 & 36,2 & 33,2 & 31,4 & 94,8 \\
\hline в том числе с молокопроводом & 16,2 & 14,9 & 14,8 & 14,6 & 14,1 & 14,1 & 99,9 \\
\hline
\end{tabular}

\section{* http://gks.ru}

Как видно из табл. 2, сокращение количества самоходной техники в 2005-2010 гг. происходило постепенно. Сокращение количества техники - естественное явление на фоне заметного уменьшения площади посевов культур и резкого роста производительности современной техники.

Основной причиной постоянного увеличения затрат на энергоресурсы в себестоимости продукции является рост цен, который происходит стихийно и не контролируется государственными органами управления. С 2001 по 2009 год наблюдалась тенденция роста цен на энергоресурсы, потребляемые сельскохозяйственными организациями. Например, цены на электроэнергию за это время выросли в 5,2 раза, топливо - в 4,5 раза, горючее и смазочные материалы - в 2,6 раза (рис. 1). И только цены на горючее и смазоч- ные материалы немного снизились в 2009 г. по сравнению 2008 г. Темпы роста цен не обосновываются производителями и поставщиками энергоресурсов, не осуществляются анализ себестоимости их производства.

Из-за повышения цен на энергоносители возник возрастающий диспаритет цен между реализуемой продукцией сельского хозяйства и потребляемыми промышленными ресурсами: за последние двадцать лет рост цен на потребляемые ресурсы в 5 раз превысил рост закупочных цен. В 2009 г. цены на электроэнергию и дизельное топливо увеличились соответственно на 14,6 и $14,4 \%$, на продукцию сельского хозяйства - только на $2,5 \%$. При этом цена на дизельное топливо в период посевной компании и уборки урожая повышалась на 30 \% по сравнению с 2008 г. 
Наиболее приемлемыми являются удельные показатели расхода энергоресурсов на единицу площади земельных угодий. Они имеют такую же тенденцию изменения, что и общий расход энергоресурсов: значительное уменьшение с 1990 по 2000 г. и дальнейшей стабилизации их расхода в 2001-2010 гг. Например, удельный расход дизельного топлива на 1 га посевной площади снизился с 173,5 кг в 1990 г. до 67,4 кг в 2000 г. или в 2,6 раза (рис. 2).

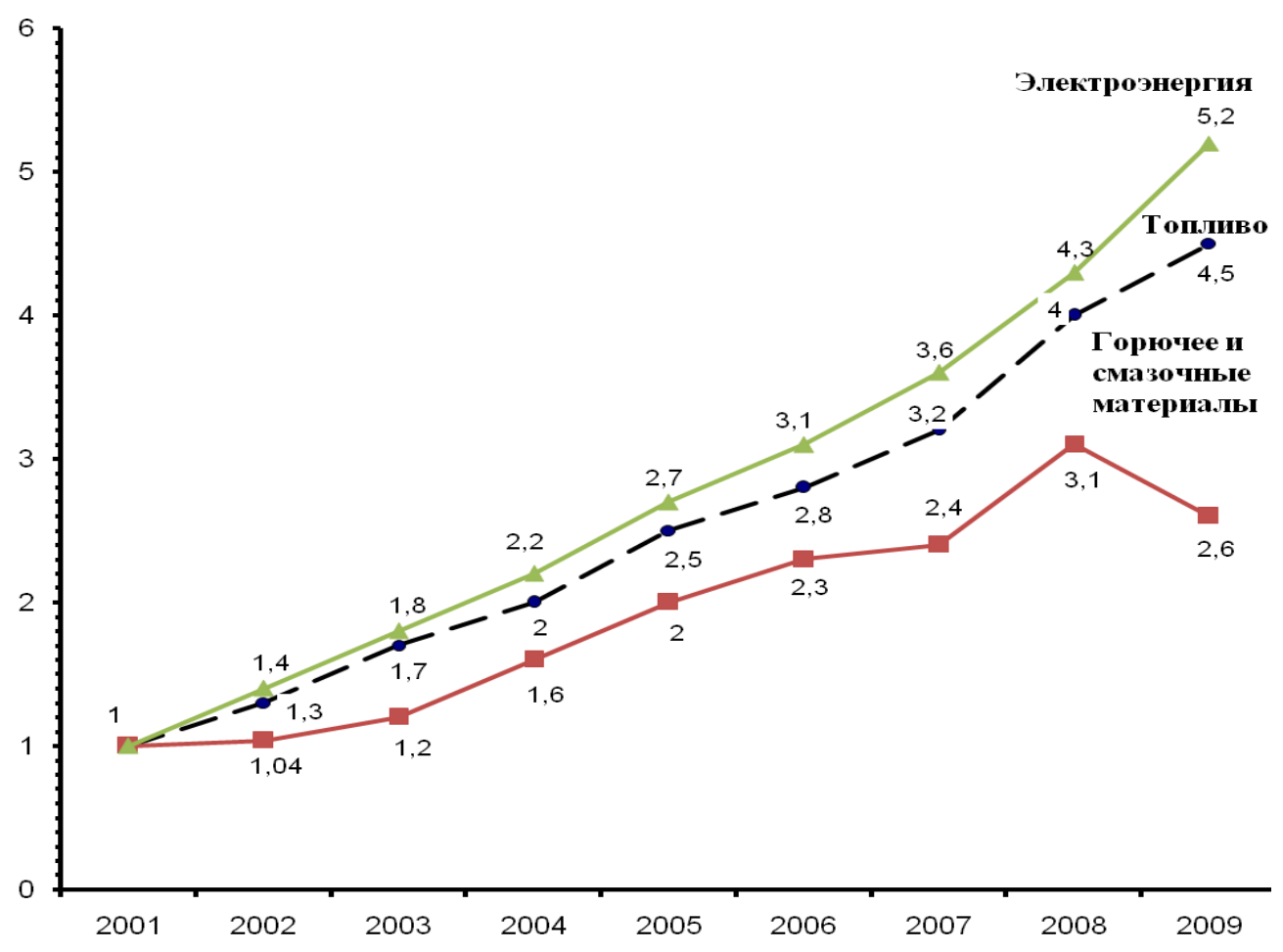

Рисунок 1 - Динамика роста цен на энергоресурсы $(2001$ г. $=1,0)$

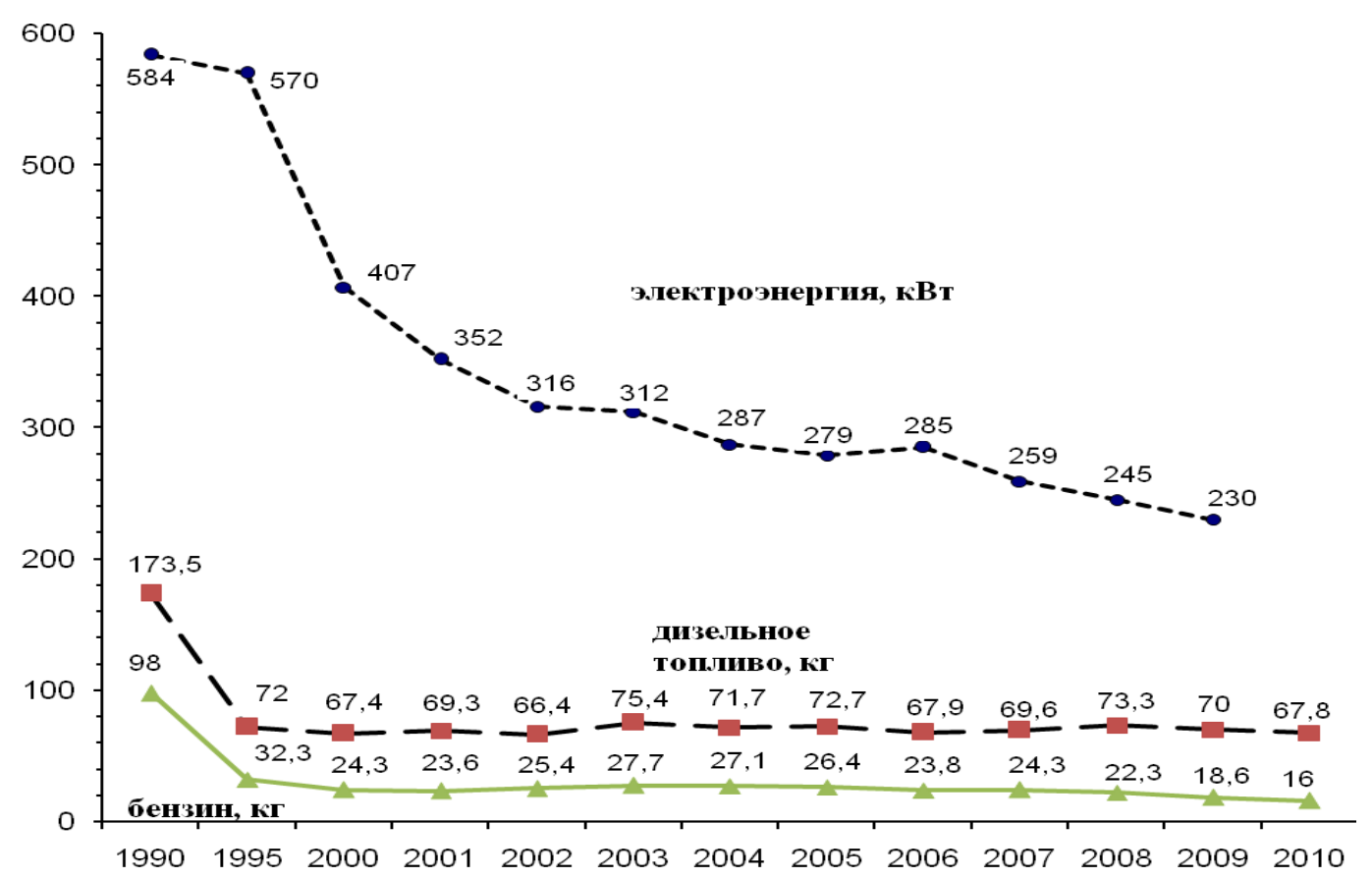

Рисунок 2 - Удельный расход энергоресурсов на 1 га посевной площади в сельскохозяйственных организациях Российской Федерации 
В последующие годы его потребление стабилизировалось, и в 2010 г. удельный расход дизельного топлива достиг величины 67,8 кг/га или на 0,6 \% больше по сравнению с 2000 г. Удельный расход бензина на 1 га посевной площади снизился с 98 кг в 1990 г. до 16 кг в 2010 г. или в 6,1 раза. Минимальный расход приходится на 2010 год. Удельный расход электроэнергии на производственные нужды на 1 га посевной площади в 1990 г. составлял 584 кВт.ч и снизился в 2000 г. до
407 кВт.ч или в 1,4 раза; в 2009 г. - до 230 кВт.ч или в 2,5 раза.

Общий расход нефтепродуктов (дизельное топливо, бензин, масла) в стоимостном выражении до 2008 г. постоянно возрастал: в 2000 г. он составлял 36,5 млрд. руб. и в 2008 г. вырос до 92 млрд. руб. или в 2,5 раза. И только в 2010 г. он снизился до уровня 70,9 млрд. руб. или в 1,3 раза по сравнению с 2008 г. (табл. 3).

Таблица 3 - Расход ресурсов в сельскохозяйственных организациях России, млрд. руб. (по данным годовых отчетов Минсельхоза РФ)

\begin{tabular}{|c|c|c|c|c|c|c|c|c|c|c|c|}
\hline \multirow{2}{*}{$\Pi / \Pi$} & 2000 & 2001 & 2002 & 2003 & 2004 & 2005 & 2006 & 2007 & 2008 & 2009 & 2010 \\
\hline & \multicolumn{11}{|c|}{ Сельскохозяйственные организации - всего } \\
\hline Нефтепродукты & 36,5 & 41,1 & 37,4 & 41,5 & 52,0 & 61,3 & 67,3 & 67,7 & 92,0 & 71,3 & 70,9 \\
\hline Электроэнергия & 7,6 & 7,8 & 11,3 & 13,6 & 15,4 & 17,0 & 18,8 & 21,0 & 25,0 & 30,0 & 34,8 \\
\hline \multirow[t]{2}{*}{ Топливо } & 3,6 & 4,6 & 4,7 & 5,7 & 6,5 & 7,7 & 8,8 & 9,7 & 10,7 & 12,1 & 14,4 \\
\hline & \multicolumn{10}{|c|}{ в том числе растениеводство } & \\
\hline Нефтепродукты & 24,9 & 28,4 & 25,6 & 28,0 & 36,0 & 43,0 & 47,8 & 48,6 & 67,7 & 52,5 & 50,7 \\
\hline Электроэнергия & 2,1 & 2,2 & 2,8 & 3,3 & 3,9 & 4,2 & 4,5 & 5,2 & 6,0 & 7,2 & 7,6 \\
\hline Топливо & 1,4 & 1,8 & 1,9 & 2,3 & 2,8 & 3,5 & 4,1 & 4,7 & 4,3 & 4,8 & 5,5 \\
\hline
\end{tabular}

Стоимость потребленной электроэнергии в 2000 г. составляла 7,6 млрд. руб., и выросла в 2010 г. до 34,8 млрд. рублей или в 4 раза (табл. 2). Но за этот период расход электроэнергии в кВт/ч снизился в 2,2 раза. То есть рост цен составил за этот период в девять раз.

Удельный расход нефтепродуктов на 1 гектар сельскохозяйственных угодий в 2000 г. составлял 258 руб. и вырос в 2010 г. до 796 руб. или в 3 раза; на 1 га пашни - с 399 до 1096 руб. или в 2,7 раза (табл. 3).
Эквивалентность обмена характеризуется динамикой объема сельскохозяйственной продукции, который необходимо реализовать для приобретения единицы материального pecypca.

В таблице 4 представлены средние цены реализации сельскохозяйственной продукции и средние цены на основные виды материально-технических ресурсов, приобретаемые сельскохозяйственными предприятиями (по Орловской области).

Таблица 4 - Средние цены реализации на сельскохозяйственную продукцию и материальнотехнические ресурсы, рублей за тонну (единицу)

\begin{tabular}{|l} 
Виды продукции, ресурсы \\
\hline - Сельскохозяйственная продукция \\
\hline Зерновые культуры
\end{tabular}

Выполненные расчеты свидетельствуют о наличии диспаритета цен на сельскохозяйственную продукцию и промышленные товары, приобретенные сельскохозяйственными орга- низациями. Цены на материальнотехнические ресурсы растут более быстрыми темпами по сравнению с ценами на сельскохозяйственную продукцию. 
Таблица 5 - Эквивалентность обмена продукцией между сельским хозяйством и промышленностью

\begin{tabular}{|c|c|c|c|c|c|c|}
\hline \multirow{3}{*}{$\begin{array}{c}\text { Виды материально-технических } \\
\text { ресурсов }\end{array}$} & \multicolumn{6}{|c|}{$\begin{array}{l}\text { Требуется продать сельскохозяйственной продукции для приобретения } \\
\text { материально-технических ресурсов, тонн }\end{array}$} \\
\hline & \multicolumn{3}{|c|}{ Зерна } & \multicolumn{3}{|c|}{ Молока } \\
\hline & $2000 \Gamma$ & $2005 \Gamma$ & 2010 г. & $2000 \Gamma$ & 2005 г. & $2010 \Gamma$ \\
\hline Комбайн зерноуборочный & 526,2 & 780,4 & 1141,4 & 388,1 & 345,8 & 540,3 \\
\hline $\begin{array}{l}\text { Тракторы сельскохозяйственные уни- } \\
\text { версальные общего назначения }\end{array}$ & 118,2 & 257,2 & 528,4 & 87,2 & 114,0 & 250,1 \\
\hline Машины почвообрабатывающие & 34,4 & 71,3 & 236,7 & 25,3 & 31,6 & 112,1 \\
\hline $\begin{array}{l}\text { Комбикорм для птиц, свиней и крупно- } \\
\text { го рогатого скота }\end{array}$ & 1,5 & 3,8 & 2,8 & 1,1 & 1,7 & 1,3 \\
\hline Удобрения & 0,47 & 4,56 & 5,87 & 0,34 & 2,02 & 2,78 \\
\hline Дизельное топливо & 2,50 & 5,53 & 3,69 & 1,85 & 2,45 & 1,75 \\
\hline
\end{tabular}

В 2010 году требуется продать большее количество сельскохозяйственной продукции для приобретения единицы материальнотехнических ресурсов, чем в 2000 году. Так в 2000 году для приобретения зерноуборочного комбайна необходимо было реализовать 526,2 т зерна или 388,1 т молока, а в 2010 году 1141,4 т и 540,3 т соответственно.
Реализовав 1т зерна в 2000 году можно было приобрести 0,4т дизельного топлива или 2,1 т удобрений, а в 2010 г. всего - 0,27 т и 0,17 т соответственно. Диспаритет цен приводит к тому, что сельскохозяйственные организации с каждым годом вынуждены тратить дополнительные средства на простое воспроизводство.

\section{БИБЛИОГРАФИЯ}

Борисов В.А., Волнова М.О. Управление инновационными проектами энергосбережения на основе концепции устойчивого развития/ Борисов В.А., Волнова М.О. // Фундаментальные и прикладные проблемы техники и технологии. 2007. № 4. C. 140-142.

Драгайцев В.И и др. Методика экономической оценки технологий и машин в сельском хозяйстве /, Алексеев К.И., Марюхненко Ж.С., Мирошников Г.А., Полухин А.А., Алпатов А.В., Грудкин А.А., Ставцев А.Н., Жуков Н.И., Новиков Ю.И. Москва 2010. 147 с.
Кантор О. Г. Оценка и оптимизация ресурсного потенциала предприятия / О.Г. Кантор, Л. А. Ганиева// Экономические науки. - 2008. - N 4. - С. 168-172.

Михайлов С.А. Основные принципы концепции всеобщего управления энергосбережением/ Михайлов С.А. //Путеводитель предпринимателя. 2010. № 8. С. 101-104.

Михайлов С.А. Обеспечение региональной энергоэффективности на основе модели стратегического управления энергосбережением/ Михайлов С.А. // Журнал правовых и экономических исследований. 2009. № 3. С. 9-12. 